\title{
El acompañamiento educativo, una mirada ampliada desde la antropología personalista
}

(Educational accompaniment, an expanded view from personalist anthropology)

\section{SONIA M. GONZÁLEZ-IGLESIAS}

Universidad Francisco de Vitoria, Madrid

s.gonzalez@ufv.es

ORCID 0000-0001-6439-0704

\author{
CARMEN DE LA CALLE MALDONADO \\ Universidad Francisco de Vitoria, Madrid \\ m.calle@ufv.es \\ ORCID 0000-0002-0387-5959
}

Resumen. En el panorama educativo actual, la transformación digital supone un desafío metodológico, pedagógico y, sin duda, relacional. En este entorno, hay diferentes propuestas que abogan por el acompañamiento como medio para afrontar este reto. Es más, podríamos decir que acompañar está de moda, con el riesgo que eso implica de limitar e incluso edulcorar su verdadero significado y alcance. Para evitarlo, proponemos volver la mirada a la naturaleza del ser humano y re-descubrir lo que realmente necesita en su proceso de crecimiento personal. Este artículo presenta un análisis del acompañamiento educativo, desvelando su dinamismo interno, explicitando las condiciones esenciales que lo hacen posible y proponiendo algunas aplicaciones 
pedagógicas que iluminen la misión de acompañar. Desde esta mirada personalista y profunda, planteamos el acompañamiento como la respuesta a una necesidad antropológica (a la medida del ser humano) y como un camino de encuentros orientados a la plenitud de la persona.

Palabras clave: Formador; encuentro; crecimiento; experiencia; dinamismo educativo.

Abstract. In today's educational landscape, the digital transformation is a methodological, pedagogical and, undoubtedly, relational challenge. In this environment, there are proposals that advocate accompaniment as a means of facing this challenge. Moreover, we could say that accompanying is fashionable, with the risk that this implies of limiting and even sweetening its true meaning and scope. To avoid this, we propose to look at the nature of the human being and rediscover what he really needs in his process of personal growth. This article presents an analysis of educational accompaniment, revealing its internal dynamism, making explicit the essential conditions that make it possible and proposing some pedagogical applications that shed light on the mission of accompaniment. From this personalist and profound point of view, accompaniment is proposed as a response to the anthropological need of being human and is configured as a path of encounters oriented towards the fullness of the person.

Key words: Formator; encounter; growth; experience; educational dynamism.

\section{Introducción}

La transformación digital y la denominada cuarta revolución industrial (Márquez Dorsch 2019) suponen un desafío metodológico, pedagógico y, sin duda, relacional para los educadores. Estamos llamados a afrontar los nuevos retos que presenta esta sociedad cada vez más compleja y sofisticada. Ya el Papa Emérito hizo explícita su preocupación por la educación, poniendo el foco en la acuñada "emergencia educativa" ante "la creciente dificultad que se encuentra para transmitir a las nuevas generaciones los valores fundamentales de la existencia y de un correcto comportamiento" (Benedicto XVI 2007).

En este entorno, proliferan estudios, formaciones, iniciativas y herramientas didácticas en las que se pone el énfasis, cada vez con más fuerza, en el acompañamiento personalizado, en sus diferentes versiones o denominaciones: mentoring, coaching educativo, counceling, tutorías ... También lo encontramos en el ámbito eclesial: el Papa Francisco es el primero en atribuir a este concepto un lugar privilegiado, introduciendo en sus intervenciones 
y documentos la misión educativa en clave de acompañamiento (Papa Francisco 2013; 2017; 2018). Incluso podríamos decir que acompañar está de moda. Pero más allá de este hecho, acompañar es, sobre todo y en esencia, la respuesta a una necesidad antropológica, a la medida del ser humano.

Quizás ahora, cuando la realidad virtual puede desvirtuar la concepción de la realidad misma y su relación con ella, es clave explicitar la necesidad que tiene el ser humano de ser acompañado. ¿Por qué es necesario el acompañamiento? Nuestro análisis se fundamenta en la antropología personalista que presenta la relación como constitutiva del ser personal $\mathrm{y}$, consecuentemente, de todo acto educativo, sea virtual o presencial. La persona es un ser-de-encuentro, crece y se desarrolla en relaciones de encuentro con la realidad, consigo mismo, con los demás, con lo trascendente (López Quintás 2002, 195-197). Estas relaciones se van entretejiendo en el tiempo y necesitan ser integradas e iluminadas: el acompañamiento queda así configurado como un camino de encuentros orientados a la plenitud de la persona.

No estamos ante un elemento más de un modelo pedagógico sino ante una clave antropológica esencial que ha de inspirar todo el proceso formativo. Un modo de comprender la misión educativa. A veces podemos reducir el acompañamiento a una función, a un modo de dirigir o solucionar problemas, incluso convertirlo en una pseudorelación terapéutica, movidos por el deseo de ayudar o aconsejar.

El acompañamiento es algo diferente: es un camino compartido de descubrimiento de la Verdad, de la Bondad y de la Belleza; un entreveramiento de encuentros vitales en los que nos pasa algo, a formadores y formandos $\mathrm{y}$, por ende, a la comunidad educativa; un ámbito donde se integran comprensión y exigencia, pues el camino de la vida es exigente, bello sin duda, pero en tensión hacia la plenitud vocacional. Algo que implica la madurez de la persona en todas sus dimensiones y una constante búsqueda del sentido de la propia vida.

El objetivo de este artículo es analizar con profundidad y amplitud este acompañamiento educativo, desvelar su dinamismo interno y explicitar las condiciones esenciales que lo hacen posible. Proponemos, desde esta mirada 
profunda, destilar algunas aplicaciones pedagógicas que iluminen la misión de acompañar, poniendo el énfasis en el formador como el método que la encarna. Entendemos el término "formador" en sentido amplio, que incluye tanto al docente como a todo aquel que contribuye en la labor educativa. Y hablamos de "formando" como estudiante universitario, aunque esta propuesta, en la medida en que hablamos de lo esencial, es extrapolable a otras etapas educativas.

Nuestra pretensión no es resolver la cuestión de la emergencia educativa, pero sí ampliar el marco de referencia actual, tantas veces centrado exclusivamente en el profesor o en el alumno (Orón Semper 2018, 242), desde una mirada sistémica que integre al formador, al formando, y al entre relacional que se genera entre ambos. El "entre" adquiere entidad propia, y es definido como "ámbito originario, inédito, constelacional, que se crea al interferirse dos o más ámbitos. No es un mero espacio físico, es un espacio lúdico, un campo de juego" (López Quintás 1998, 300).

Tomamos a López Quintás, considerado como el principal representante español del personalismo dialógico (Muñoz García 2015, 133; Cañas Fernández 2008, 241), como autor de referencia por su propuesta para superar la emergencia educativa (2019, 31-46), con un método de descubrimiento y un camino de crecimiento que culmina "en el encuentro y en el ideal de la unidad” (2014, XXXVIII). El encuentro aparece como idea vertebradora del pensamiento quintasiano e hito decisivo del crecimiento humano. También como categoría determinante en la filosofía personalista para superar el individualismo y ordenar al hombre hacia la verdad.

Entendemos el encuentro como movilizador del crecimiento de la persona y el acompañamiento como respuesta que sostiene todo el proceso vital. Se integra así una antropología personalista y una pedagogía relacional.

Desarrollaremos el contenido de este artículo (González Iglesias 2015) ${ }^{1}$ en tres apartados:

1 Este artículo es parte de la investigación realizada por Sonia González Iglesias, “El poder transfigurador del encuentro en el desarrollo integral del adolescente. Una propuesta desde el método de López Quintás” (Tesis Doctoral, Universidad Francisco de Vitoria, 2015) 
1. Dinamismo interno del acompañamiento: despertar, descubrir, decidir.

2. Condiciones específicas del acompañamiento: mirada, escucha, esperanza y perdón.

3. Algunas aplicaciones pedagógicas y prospectiva.

\section{Dinamismo interno del acompañamiento: despertar, descubrir, sostener decisiones}

Etimológicamente acompañar proviene de cum-panis, compartir el mismo pan. Significa poner en juego ambas vidas, con sus diferentes grados de experiencia, para poder llegar a un aprendizaje mutuo. "Acompañar es, de formas diversas, compartir el camino y sus experiencias” (Funes Artiaga 2011, 194).

Efectivamente, acompañar guarda una relación semántica con la palabra camino, pues no es otra cosa que caminar junto a otro (Domínguez Prieto 2017, 12). El ser humano es un homo viator, el único ser que viaja, "y que sólo cuando está en camino es verdaderamente hombre” (Bueno 2000). Somos esencialmente dinámicos, en crecimiento durante toda nuestra vida, tensionados entre lo que somos y lo que estamos llamados a ser. Es cierto que no tenemos trazada una ruta inequívoca, sino que más bien llevamos inscritos anhelos, preguntas -quién soy yo, qué espero de la vida, dónde buscar mi plenitud, cómo amar y sufrir- que nos movilizan y nos convierten también en homo quaerens, alguien que desea respuestas. Fue Frankl quien acunó la expresión tan sugerente de voluntad de sentido $(2004,78)$ : aquella que impulsa al hombre a la búsqueda de razones para vivir. No se puede vivir en la conciencia del no-sentido absoluto.

En esta tarea nadie puede ser sustituido, pero necesitamos ser acompañados. "Paradójicamente sólo yo, pero no yo solo puedo pasar a la acción después de haber tomado una decisión personal, y es ahí, donde el otro se nos desvela como alguien necesario, para poder sostener esa decisión en la acción y en el tiempo" (de la Calle Maldonado et al. 2020, 313). En este sentido, Domínguez Prieto entrevera y relaciona magistralmente la tarea de educar con la de acompañar: 
El término "educar" posee una doble raíz. En primer lugar, educere, que significa extraer y actualizar todo lo que ya hay en la persona, sacar a la luz toda la riqueza que en ella hay. Por otro, educare significa nutrir, alimentar, ofrecer posibilidades para que el otro pueda crecer. El docente, de este modo, está llamado a acompañar a la persona para que sea quien está llamada a ser [...] Para eso, el docente tiene que dar respuesta a las características del dinamismo personal que permite el encuentro: acoger al otro y darse al otro $(2003,20)$.

Educar se convierte en sinónimo de acompañar, guiar e impulsar a la persona en su camino personal de maduración como hombre o mujer, para alcanzar su plenitud vocacional. De forma sintética y magistral, queda recogido el sentido del acompañamiento y su finalidad última: que la persona descubra y alcance por sí misma aquello para lo que ha sido llamado. En esta relación educativa, el peso está en el acompañado que debe descubrir su llamada y responder libremente a ella, mientras el acompañante será un formador que iluminará, exigirá y sostendrá, en su caso, su decisión. Añadiendo un matiz esencial para que esto sea posible: el encuentro como ámbito de la relación formativa, en la que ambos se dan y se acogen.

La relación es esencial en el ser humano y el encuentro es a la vez constitutivo de la relación propiamente humana. No solo la persona crece y se desarrolla a través de experiencias de encuentros, sino que ella misma, por naturaleza, es ser de y para el encuentro. El hombre es fruto de un encuentro; su esencia y fin, el encuentro con los otros y con el Otro (López Quintás 1998, 186-189). Tiene sentido que nuestra vida se haga, se configure, a través de encuentros. No es opcional, es parte de nuestro modo de ser y de crecer. De ahí que el encuentro se convierta en categoría para iluminar la comprensión profunda del ser humano y sea "el núcleo de la formación integral. Porque es la instancia, el lugar y el momento en el que el sujeto es más sí mismo” (Agejas 2013, 175). El encuentro es el método privilegiado para el crecimiento y desarrollo de la persona.

Es importante enfatizar la implicación del crecimiento y el encuentro, como dos caras de una misma moneda. Para el ser humano crecer es ley de vida, un deber que cumplir con responsabilidad. No crecemos de forma instintiva, como las plantas o los animales, y no podemos optar entre crecer 
o no crecer; iría contra una ley básica de nuestro ser. Surge, entonces, una pregunta clave: ¿cómo debemos crecer? (López Quintás 1998, XX; 2002, 6-7). Asumiendo las posibilidades que nos vienen dadas por nuestro entorno, e integrando nuestro desarrollo fisiológico, psíquico y espiritual. En definitiva, jugando y experimentando el encuentro como modo privilegiado de unión con la realidad, eminentemente creativo y generador de luz. No es resultado automático de la vecindad o proximidad, es fruto de una decisión esforzada y exige una serie de condiciones en los seres que lo viven (López Quintás 2009, 48-54).

Ahora bien, el camino del crecimiento es largo e ilimitado según el pensamiento quintasiano. Ilimitado en el sentido de que la vida no deja de presentarnos oportunidades para seguir creciendo, sin perder de vista el fin de la tarea educativa. Y esto no se alcanza caminando sin más, implica "ir logrando metas” en una progresión ascendente ${ }^{2}$. Si el crecimiento es ilimitado, el acompañamiento que lo sostiene también. Y es auténtico en la medida en que responde a la verdad del ser humano, es decir, en tanto en cuanto le humaniza, le posibilita ese desarrollo personal. No se trata de encontrarse por encontrarse, sino caminar juntos para crecer. La ley del crecimiento integral hacia la plenitud del ser humano marcará los cauces, posibilidades y límites del camino, apuntando siempre hacia arriba, siempre más alto.

El acompañamiento se convierte así en un camino armonizado de encuentros, y desencuentros, a lo largo de un tiempo significativo y continuado, orientados a la plenitud de la persona: encuentros con los demás, consigo misma, con la realidad, con Dios. Esta es la naturaleza propia del acompañamiento y su grandeza: su capacidad de generar encuentros transformadores entre los formadores y formandos.

A continuación, describimos con mayor hondura el dinamismo interno de este modo de acompañar, que se concreta en la tarea educativa de despertar, descubrir y sostener decisiones a través del acompañamiento (González Iglesias y Agejas Esteban 2019, 181-187).

2 "Una formación ética bien fundamentada no se reduce a adquirir ciertos conocimientos; supone seguir un proceso de crecimiento personal, de configuración de nuestra segunda naturaleza, nuestro modo de ser o êthos". (López Quintás 2009, 34) 


\subsection{Despertar}

El ser humano es un buscador, aunque muchas veces constatamos que esa búsqueda está adormecida o anestesiada, porque no tiene capacidad para ponernos en camino. El primer paso en el acompañamiento será despertar preguntas, pues nadie busca lo que no desea. Marion afirmaba que "hay respuestas que nacen muertas porque responden a interrogantes no planteados". Iniciar con la pregunta lleva a cambiar la perspectiva del formador, tantas veces centrada en dar respuestas, aunque sean ciertas. Implica ejercitar una mirada profunda capaz de ver la hondura de cada persona, confiar en la grandeza de su corazón e identificar su deseo de plenitud.

Sin interpelación, la vida se puede estancar. La pregunta inicia el camino del homo viator y del homo quaerens, condición compartida por formadores y formandos: seres abiertos que se cuestionan y desean encontrar respuestas para seguir creciendo. En permanente necesidad de reflexionar sobre lo que hacemos, quiénes somos y quiénes queremos ser. Además, cada pregunta inaugura un camino distinto, que puede llevar también a un lugar diferente.

De las preguntas surgen entonces actitudes de sobrecogimiento, respeto, y genuino asombro (Agejas Esteban 2013, 22-24), que sólo nace "cuando el hombre entiende su existencia, la vida y el Universo como un don". En este sentido, López Quintás invita a "renovar de raíz” nuestra manera de comprender la formación "hacia formas de enseñanzas más vitales, más semejantes al modo que tiene la vida de crecer -que es un proceso orgánico de dentro afuera, eminentemente creador y fecundo" (1975, II: 131-132).

No se trata de impactar con dinámicas que atraigan superficialmente su atención. Se trata más bien de desvelar, sacar a la luz, de dentro afuera. Saber despertar sus preguntas existenciales y ponerlas en juego para, desde ellas, iluminar su camino de crecimiento. Serán existenciales en cuanto que toquen su vida, con la gradualidad debida: desde el interés inicial por una asignatura hasta llegar a lo profundo de la persona. No es lo mismo preguntar qué vas a hacer este fin de semana a qué esperas de este fin de semana. La búsqueda pasa de la agenda (lo planificado) al mismo corazón (lo deseado).

La tarea del formador será, principalmente, generar ámbitos donde se puedan expresar o identificar las preguntas. Muchas veces será la asignatura, 
la experiencia formativa o, sobre todo, la propia vida, la que nos brinde esos espacios para interpelarnos; en otras, el formador puede recurrir a cierta provocación o regalar una pregunta existencial al acompañado. Es crucial dar con las preguntas adecuadas, que sean relevantes y al mismo tiempo, condicionantes, movilizadoras, siguiendo el genuino modelo socrático.

"Ahora bien: son sus preguntas, no las nuestras" (González Iglesias 2012, 120). En experiencias de encuentros con jóvenes de edades y países diferentes, aún nos sorprende cómo una simple hoja en blanco y un breve tiempo de silencio se convierten en llaves poderosas para desvelar y descubrir sus inquietudes más profundas, tales como: ¿para qué las humanidades en Ingeniería?, ¿dejaré huella?, ¿y si no soy tan bueno como esperan?, ¿de verdad existe el amor verdadero?, ¿a qué esperas para dar el primer paso?, ¿seré el culpable de la separación de mis padres? ¿dónde estaba Dios cuando yo sufría tanto?, ¿por qué me siento tan solo que me quiero morir?

En definitiva, el acompañamiento comienza con un encuentro que despierta el deseo y que convierte en protagonista al formando que se pone en marcha. Como afirma López Quintás (1975, II: 163), “todo el saber humano es «un saber buscado», un saber vibrante, fontanal, luz en eterna alborada, recién estrenada y viva”. Comienza así el dinamismo del crecimiento y del encuentro.

\subsection{Descubrir por sí y para sí}

Descubrir implica, por un lado, conectar con la pregunta que se ha despertado. Por otro, encontrar respuestas en primera persona, con toda la fuerza de la novedad para la propia vida. No se trata, por tanto, de transmitir ideas para resolver preguntas, se trata de ofrecer espacios, metodologías, que ayuden a descubrir la verdad.

Si había gradualidad en las preguntas, también la hay en las respuestas. Ya Marcel distinguía entre problemas y misterios. Los primeros requieren de una solución: ¿cuál es la ventaja de trabajar con células madre del cordón umbilical de un bebé? Los segundos nos abren a la grandeza de lo que somos, incluso al misterio: ¿qué sentido tiene esta vida que tengo en las manos, 
hasta dónde y cómo respetarla? En ambos se precisa de nuestra razón para descubrir respuestas, aunque con métodos diferentes y complementarios al mismo tiempo. Sería imposible desvelar el sentido de la vida sólo desde el método empírico-matemático, como pretende el cientifismo.

El reto de descubrir por sí y para sí apela a la experiencia como categoría de aprendizaje, en su sentido más amplio, como "la comprensión adquirida a través de un viaje. Esta experiencia sólo puede adquirirse en la medida en que se hace, y sólo puede hacerla el que se abandona a sí mismo y se pone en marcha" (Balthasar 1985, 209). Seguimos con la confianza puesta en la persona que busca, que tiene la capacidad de conocer la realidad, de encontrarse con ella, recuperando el valor de la experiencia como campo de juego en el que la persona puede implicarse y desplegar todas sus facultades y dimensiones. No vale, por tanto, cualquier experiencia, sino aquella que le permita participar y colaborar en primera persona. Es necesario ofrecer esas experiencias reversibles (López Quintás 2002, 105-114; 2009, 39-41), en donde surja el encuentro con lo real, porque la misma verdad es mucho más que una teoría o una técnica, es una experiencia (Agejas 2013, 137-151).

De todas esas experiencias, los encuentros interpersonales serán los más transformadores. Lo que más afecta a una persona es otra persona. "El hombre contemporáneo escucha más a gusto a los que dan testimonio que a los que enseñan [...] o si escuchan a los que enseñan, es porque dan testimonio" (Pablo VI 1975, n 41). El formador no debe ser perfecto, pero sí testigo de lo que habla. Se necesitan "guías adecuados, personas que conozcan a fondo el proceso humano de desarrollo" (López Quintás 2009 , 29). De esta manera, la respuesta ante una pregunta existencial será la vida misma del formador.

La tarea del formador será: en primer lugar, proporcionar experiencias reversibles en las que poder descubrir, por dentro y en clave personal, las certezas que necesita para seguir caminando. En segundo lugar, reflexionar e iluminar esas experiencias, dando espacio y tiempo para destilar respuestas. Y, en tercer lugar, sumamente relevante, discernir y jerarquizar, pues no todas tienen por qué ser igualmente válidas: unas serán certezas para la asignatura, otras para la profesión y algunas, para la propia vida. 
De esta manera, estaremos ayudando a adquirir sabiduría de vida, no sólo acumulando conocimientos o impactos formativos, que pueden sorprender, pero no necesariamente formar.

La sabiduría es algo que está ligado a la vida. No es simplemente el conocimiento de los fenómenos de la vida en serie, uno detrás de otro como podría hacerlo también un sistema teórico, sino un penetrar en el misterio de la vida, en sus conexiones no inmediatamente visibles. A la sabiduría se llega a través de una reflexión precisa sobre la experiencia, no sólo la propia sino también de los otros (Rupnik 2013, 121).

En definitiva, "el que descubre algo valioso por su cuenta -aunque sea con ayuda externa- queda interiormente persuadido de su valor y bien dispuesto para asumirlo en su vida y comunicarlo a otros de forma convincente" (López Quintás 2009, 13). El acompañamiento reclama, por lo tanto, “un método que proceda por vía de descubrimiento y suscite admiración ante las realidades y los acontecimientos descubiertos [...]. Los conocimientos son necesarios, pero más lo es descubrirlos por propia cuenta” (López Quintás 2009, 17-18). La respuesta existencial entonces conectará la realidad concreta del formando, con toda su existencia.

\subsection{Sostener sus decisiones}

Las verdades descubiertas no son solo para saberlas, sino para vivirlas. El signo más claro de que han tocado a una persona es que se han convertido en decisión. Es el momento conclusivo, pero no de cierre, del camino de aprendizaje y acompañamiento, que sin duda abrirá a nuevas preguntas, descubrimientos y decisiones, en una espiral de crecimiento y de profundización. La persona ejercitará su libertad de modo muy concreto, con responsabilidad e integrando inteligencia, afecto y voluntad en una acción aterrizada.

También hay gradualidad en las decisiones, según la intensidad y la hondura con que toquen la vida, desde las que afecten a cuestiones más parciales hasta las que lleguen a lo profundo de la persona, a esas opciones fundamentales que ofrecen una orientación existencial: desde decido estudiar 
para aprender y no simplemente para aprobar, hasta opto por respetar la vida en el ejercicio de mi profesión.

Ahora bien, desde el realismo antropológico, sabemos que una decisión no conlleva automáticamente una acción. Del dicho al hecho hay mucho trecho, según la sabiduría popular, y posiblemente nuestra experiencia nos lo confirma en demasiadas ocasiones. El desafío no acaba con la toma de decisiones, sino con su encarnación en lo concreto. La limitación, precariedad y la necesidad del otro se tornan especialmente visibles en estos momentos. «Aunque la persona tiene que realizar su vida, no es autosuficiente para realizarse. Ha de apoyarse en la realidad y, sobre todo, en otras personas. En este sentido, el docente tiene una tarea de especial relevancia» (Domínguez Prieto 2003, 30). El formador se convierte en apoyo y soporte para que el formando se sienta seguro en su proceso de crecimiento.

Ayudar a abrazar el error es clave y será posiblemente cuando más necesitemos ser sostenidos para asumir que no buscamos ser perfectos, sino perfeccionarnos, crecer hacia lo que nos hace plenos. Podemos equivocarnos y convertir el error en una oportunidad de aprendizaje, de plantear nuevas preguntas que ayuden a seguir en esa espiral de profundización: ¿qué me ha llevado a hacer lo que no quería? ¿por qué me siento frustrado? ¿por qué me siguen queriendo? Se necesita experimentar una compañía incondicional dejando espacio y oportunidad al formando para hacerse responsable, para sentirse libre. Es necesario estar cerca y luego, dejarle ser.

Ese despertar, descubrir, decidir no acontecen necesariamente en tres momentos sucesivos o distintos, más bien se presentan entreverados en el tiempo, retroalimentándose (aunque en ocasiones pueda primar uno sobre los otros).

El dinamismo del acompañamiento queda sintetizado de forma sencilla y pedagógica así: ejercitarse en el arte de despertar preguntas existenciales para descubrir juntos respuestas verdaderas que nos lleven a sostener decisiones en orden a nuestra plenitud. También la plenitud posible, la actual. Un dinamismo en el que quedan entrelazados y comprometidos el corazón, la inteligencia y la voluntad del formando, sus relaciones, en síntesis, toda su persona. 


\section{Condiciones específicas del acompañamiento: mirada, escucha, esperanza y perdón}

La relación educativa está constituida por el encuentro de dos libertades soberanas. El acompañamiento, por tanto, no es unidireccional sino recíproco. Nos pasa algo. Se da una reciprocidad o reversibilidad como en todo encuentro, dar y acoger. Pero en este caso hay también "disimetría”: cada uno de los implicados tendrá una responsabilidad específica. En el caso del formador, tiene una experiencia y sabiduría mayor que la del acompañado y, en consecuencia, también responsabilidad mayor en llevar el proceso a buen puerto. Se compromete nada más y nada menos a que el formando "llegue a ser quien está llamado a ser" (Domínguez Prieto 2012, 36-37). De esta manera, se convierte en pieza clave en el camino de la vida del formando.

La importancia de este formador es primordial para exponerle a experiencias reversibles eminentemente creativas. Y, sobre todo, para acreditar con su propia vida que este camino es posible. En este sentido, el formador está llamado a "comunicarse a sí mismo", salir de sí y ofrecerse a los otros, expresarse. (Domínguez Prieto 2012, 18-28). Podemos afirmar que el método lo encarna y lo hace visible el propio formador. Las inquietudes existenciales de los formandos no tienen como respuesta sólo unos contenidos o una metodología innovadora. La respuesta es otra vida: la de aquel que le acompaña y que se pone en camino con gratuidad y comprometido con el destino de su acompañado.

Karol Wojtyla, desde su propia experiencia de profesor universitario en la Universidad de Lublin, hablaba de la pastoral del acompañamiento (Weigel 1999, 297-302) como la mejor vía para el crecimiento integral, tanto de alumnos como de profesores. En una correspondencia con una de sus discípulas, nos dejó el legado de una frase tan sabia e iluminadora como ésta: "La persona que más me necesita objetivamente es a su vez, para mí, objetivamente, la persona que más necesito" ${ }^{3}$. Mirar así a los formandos, como aquellos que más necesita, cambia la perspectiva del formador, superando

3 Extracto de una carta de Karol Wojtyla a Teresa Heydel Zyczkowska. La cursiva es del propio Wojtyla. 
la tentación de sentirse obligado a saber o acertar en todo, y abriéndose con sencillez a los descubrimientos de los propios formandos.

Nos parece sumamente relevante explicitar las condiciones que consideramos esenciales para acompañar, actitudes que tendrán que ejercitar tanto formandos como formadores, pero serán éstos últimos los principales responsables de encarnarlas. Son las siguientes:

a) Una mirada profunda, el paso del ver al mirar. Para elevarnos al nivel relacional, necesitamos ejercitar una mirada, con capacidad de escrutar la realidad y, desde una actitud reverencial, descubrir en ella toda su verdad y su riqueza. Pasar de una mirada limitante, que seduce o controla, a una mirada honda, que no se quede en las apariencias y penetre hasta la riqueza de lo real (López Quintás 2014, 612-613) Una mirada posibilitadora que confía, verdadera.

Esta mirada profunda condiciona nuestra relación con los demás en general, y en particular con los formandos (González Iglesias y de la Calle Maldonado 2019). Nos pone en relación con la totalidad del ser, con su misterio, con lo esencial. Ejercitar esta mirada apela a nuestra libertad y responsabilidad. "Yo decido cómo miro según cómo quiero vivir las cosas [...], mirar es una acción al servicio de la voluntad de vivir” (Guardini 2000, 200).

Para un joven, esta mirada tiene una importancia capital. Su tarea principal es conocerse y aceptarse, para poder elevarse y superarse. Sin esa mirada profunda, ampliada, de largo alcance (López Quintás 2014, 612-613), sin la mirada cordial de sus formadores, difícilmente la cumplirá con verdad y con sincera estima.

Mirar así y dejarse mirar así son experiencias reversibles paradigmáticas, que despiertan a la persona, aún sin haber mediado palabra alguna. Todos hemos podido experimentar esas miradas que nos anulan y o ningunean y miradas que nos dan alas, que descubren lo valioso de lo que somos y nos empujan a decidir seguir caminando, con confianza y esperanza. Una mirada así reconoce y estima la belleza de cada persona, y allana el terreno para un encuentro en la verdad. 
b) Escucha integral, el paso del oír al escuchar. El sentido de la escucha se ha relacionado siempre con el lenguaje y la comunicación entre personas, atendiendo a sus palabras. Pero cuando decimos escucha integral no queremos atender sólo a lo que nos dicen, sino a lo que nos quieren decir con sus gestos, sus expresiones, sus afectos... Oír con especial intensidad a la realidad entera, que de forma permanente nos interpela, y nos mueve a responder. Es un oír profundo, que se asemeja al obedecer (López Quintás 2014, XXV) La categoría de profundidad también transforma nuestra capacidad de oír en una actitud de acogida y comprensión. Esa es su pretensión: aguardar, acoger. Escuchar supone una espera eminentemente activa, no indiferente o pasiva.

El oído es el centro de la facultad sensitiva, pues en su ámbito de silencio penetra tanto el ruido ensordecedor, como el sonido armónico que “conmueve al corazón a la escucha” (Balthasar 1985, 349). Para escuchar hay que hacer silencio, vaciarse de uno mismo para abrirse activamente a lo que sucede, dejar resonar en el interior la voz del otro. Ensayar el silencio, sin ansiar soluciones rápidas, es todo un desafío. Como decía Masson, el hombre supera al animal con la palabra, pero con el silencio se supera a sí mismo.

Para el formando, por su parte, ejercitar esta escucha le permitirá descubrir cuál es su llamada y su vocación, y le preparará para que su respuesta sea consciente, y en la medida de su edad, madura y responsable.

La escucha es la aliada para descubrir y discernir. Sin escucha, no hay encuentro con la realidad. Sin encuentro, no es posible el acompañamiento hacia la plenitud de vida.

c) La esperanza, entendida como estado de ánimo por el que se cree que es posible aquello que se pretende. Mounier afirma que "el niño no sabe esperar, sus deseos exigen satisfacción inmediata. Desde este punto de vista, toda la educación es aprendizaje de la espera” (1993, 2: 326). Más aún el joven, que está inmerso en un proceso vertiginoso de cambios e inquietudes, necesita un contrapunto de serenidad, de hacerse a fuego lento, con la paciencia del que intuye que merece la pena esperar. 
Sigue diciendo Mounier, que "por encima de la espera está la esperanza, más generosa que la espera, porque renuncia a la determinación de las expectativas inmediatas y de los cálculos inquietos para ofrecer una amplia confianza incondicional a un futuro aceptado como radicalmente bueno" (1993, 2: 327). La confianza que abraza también la caída y el error, porque no se apoya en que no va a volver a caer, sino que puede levantarse y seguir caminando.

Esta es la esperanza que necesitan los formandos cuando ellos no pueden ni saben aún ejercitarla: una mirada esperanzadora para afrontar su presente y confiar en el futuro, para saberse queridos por lo que son hoy y por lo que están llamados a ser mañana.

d) El perdón, entendido como el don, un regalo. Somos imperfectos y limitados con una tendencia fuerte al individualismo, al egoísmo, al deseo de dominar y sobresalir a costa de los demás. Los desencuentros se dan frecuentemente en nuestras relaciones humanas.

Por ello, el perdón se convierte en elemento clave para poner bases sólidas y realistas en el crecimiento humano. Un perdón a priori, como condición previa a todo acompañamiento. El perdón es relacional: pedir perdón y perdonar.

La experiencia de perdonar (Crespo 2004, 91-126) supone, por un lado, la purificación de la memoria. Y por otro, llegar a apreciar el valor de la persona que transciende en mucho la ofensa cometida. Porque si reducimos la persona a su falta, podremos superar el enfado o incluso conceder una disculpa intelectual, pero no estaremos perdonando a la persona en su totalidad.

La experiencia de pedir perdón implica un reconocimiento de la culpa y del mal cometido. Una aceptación de la limitación y, sobre todo, un arrepentimiento sincero. Como diría Scheler, el arrepentimiento es «una forma de autocuración del alma», el camino para obtener las fuerzas perdidas. Implica el compromiso de no volver a cometer esa falta. Es abrirse al cariño de la persona dañada para con su perdón, purificar también su propia memoria. 
La experiencia de saberse perdonado restituye en el amor, en la confianza, y en la creación de encuentro más profundo y verdadero. Podríamos decir, en definitiva, que el perdón es una experiencia eminentemente creativa, con capacidad de transfigurar los desencuentros más desgarradores en encuentros de alta calidad y unidad.

De estas cuatro condiciones se desprende un círculo virtuoso de autenticidad, generosidad, fidelidad, asombro, paciencia, respeto, estima... Genera admiración y asombro, profunda gratitud por la reciprocidad en el crecimiento. Desde la fecundidad del acompañamiento, se refuerza la decisión de vivir conforme a sus condiciones y exigencias, se enriquece la vida. De esta forma "no se educa en virtudes por enseñar comportamientos y discursos teóricos, sino porque las personas hacen un proceso interior de crecimiento personal" (Orón Semper 2016, 28). El acompañamiento exige lo mejor de mí y me ofrece lo mejor del otro.

\section{Algunas aplicaciones pedagógicas y prospectiva}

A la luz del análisis que hemos realizado, destacamos algunas posibles aplicaciones pedagógicas sobre el acompañamiento sintetizadas en tres grandes bloques:

a) Vivir el dinamismo integral e integrador del acompañamiento abarca a toda la persona (inteligencia, afectos y voluntad) y genera una espiral virtuosa de crecimiento. La metodología del acompañamiento es eminentemente experiencial: nos pasa algo. Es necesario atreverse a poner en juego a toda la persona, para que despierte, descubra y decida lo que le hace crecer de forma armónica. Por eso es integral, abarca todas sus dimensiones, e integradora, genera cada vez mayor unidad interior. En el encuentro el formando descubre como valiosas las exigencias que le permiten entrar en relación auténtica con los demás, porque le llenan de alegría, entusiasmo y sentido. Las reconoce y asume como certezas para su vida, y desde ellas, puede tomar las opciones vitales que configurarán su personalidad. 
b) Acompañar es un arte e implica aprender a formular preguntas, iluminar descubrimientos y sostener en la toma decisiones, escuchando siempre a la persona y lo que le sucede en ese momento.

Comprender la educación desde este paradigma del acompañamiento, supone un cambio de mirada y un ritmo educativo diferente al que se centra solo en el contenido, en dar respuestas. Es necesario encontrar el tiempo, silencio y metodología adecuada que abran espacio a la reflexión, el discernimiento y la síntesis personal, respetando la gradualidad de cada quien.

Esto necesita de nuevas metodologías e incluir las TICs (tecnologías de la información y la comunicación), pero sin olvidar poner el peso en la dimensión relacional y teleológica: en el entre que sucede entre formador y formando y en el para qué, el fin último o propósito del acompañamiento.

c) Asumir la tarea de acompañar como un reto personal, porque ha de encarnarse en primera persona: el método, desde la perspectiva del acompañamiento, es el propio formador. Él es quien principalmente ha de poner en juego las condiciones para que pueda darse un nosotros: la mirada, la escucha, la esperanza y el perdón. Y esto no se improvisa, no es una función ni una técnica. Es un modo de ser, de estar en la educación, en definitiva, es una actitud vital. Porque si el acompañamiento es respuesta antropológica, no sólo responde a la educación, sino a la vida.

A modo de prospectiva, esbozamos algunos temas de la línea de investigación en la que se integra este artículo, y que pretende seguir ampliando la mirada sobre el acompañamiento educativo desde la antropología personalista:

- el acompañamiento comunitario, porque se acompaña en comunidad, se es acompañado por la comunidad y se acompaña $a$ comunidades. Persona y comunidad se afectan y se interpelan mutuamente. Esto se materializa en la creación de comunidades docentes y de aprendizaje, en el fomento del trabajo en equipo que genere relaciones interpersonales fecundas. 
- el acompañamiento de los pares: los amigos y compañeros como agentes imprescindibles en el acompañamiento. El formador no puede ser un francotirador, sino que está llamado a pertenecer y compartir misión.

- el acompañamiento virtual o en red: el reto de velar por las nuevas formas de conectividad o en red (Industria 4.0), con los desafíos éticos que ya se están planteando.

Juan Pablo II afirmaba que «la cultura es un modo específico del "existir” y del "ser” del hombre» (1980) Terminamos con el compromiso de impulsar una cultura de acompañamiento a través de la dinámica creativa del encuentro. Algo que se descubre y se encarna, desde la experiencia de que acompañar es sorprendentemente fecundo y necesario para la tarea de educar hoy.

\section{Bibliografía}

Agejas Esteban, José Ángel. 2013. La ruta del encuentro: una propuesta de formación integral en la universidad. Madrid: Universidad Francisco de Vitoria.

Balthasar, Hans Urs von. 1985. Gloria. Madrid: Ediciones Encuentro.

Benedicto XVI. 2007. "Discurso en la inauguración de los trabajos de la Asamblea Diocesana de Roma”. La Santa Sede. 11 de julio de 2007. http://www. vatican.va/content/benedict-xvi/es/speeches/2007/june/documents/hf_benxvi_spe_20070611_convegno-roma.html.

Bueno, Gustavo. 2000. “Homo viator. El viaje y el camino, 2000”. En Caminos Reales de Asturias, de Pedro Pisa, 15-47. Oviedo: Pentalfa. http://www.filosofia.org/ aut/gbm/2000pisa.htm?fbclid=IwAR38qcuxCp98g9jEtIjH5NipM3V0JBBbdHA7mY_dQ2_GWq3a6Wgm5syacAI.

Calle Maldonado, Carmen de la, Cecilia Castañera Ribé, y Pilar Giménez Armentia. 2020. "La incomunicabilidad del misterio del sufrimiento". Comunicación y Hombre $\mathrm{n}^{\circ}$ 16: 303-15.

Cañas Fernández, José Luis. 2008. “La hermenéutica personalista de Alfonso López Quintás”. En Ocho filósofos españoles contemporáneos, de José Luis Caballero Bono, 452. Colmenar Viejo (Madrid): Diálogo filosófico.

Crespo, Mariano. 2004. El perdón: una investigación filosófica. Madrid: Encuentro. Domínguez Prieto, Xosé M. 2003. Ética del docente. Madrid: Fundación Emmanuel Mounier. 
Domínguez Prieto, Xosé M. 2017. El arte de acompañar. 2. ${ }^{\text {a }}$ ed. Madrid: PPC.

Frankl, Viktor E. 2004. El hombre en busca de sentido. Traducido por José Benigno Freire. Barcelona: Herder.

Francisco. 2013. "Evangelii Gaudium: Exhortación Apostólica sobre el anuncio del Evangelio en el mundo actual”. La Santa Sede. 24 de noviembre de 2013. http://w2.vatican.va/content/francesco/es/apost_exhortations/documents/ papa-francesco_esortazione-ap_20131124_evangelii-gaudium.html.

Francisco. 2017. “A los participantes en la Plenaria de la Congregación para los Institutos de Vida Consagrada y las Sociedades de Vida Apostólica”. 28 de enero de 2017. http://www.vatican.va/content/francesco/es/speeches/2017/january/ documents/papa-francesco_20170128_plenaria-civcsva.html.

Francisco. 2018. “Gaudete et exsultate: Exhortación Apostólica sobre la llamada a la santidad en el mundo contemporáneo". 19 de marzo de 2018. http://www. vatican.va/content/francesco/es/apost_exhortations/documents/papa-francesco_esortazione-ap_20180319_gaudete-et-exsultate.html.

Funes Artiaga, Jaume. 2011. 9 ideas clave: educar en la adolescencia. Barcelona: GRAÓ. González Iglesias, Sonia $\mathrm{M}^{\mathrm{a}}$. 2012. ECyD book. Pozuelo de Alarcón, Madrid: Centro de Estudios para la Adolescencia y la Juventud, Universidad Francisco de Vitoria. González Iglesias, Sonia Ma. 2015. “El poder transfigurador del encuentro en el desarrollo integral del adolescente. Una propuesta desde el método de López Quintás”. Madrid: Universidad Francisco de Vitoria.

González Iglesias, Sonia Ma , y José Ángel Agejas Esteban. 2019. “Un modelo pedagógico universitario renovado conforme a la razón ampliada”. En Diálogo entre ciencias, la filosofía y la teología: II Congreso Razón Abierta, 24-25 de septiembre de 2018, Universidad Europea de Roma (Roma), de María (Coord.) Lacalle Noriega, 1. ed, 175-90. Colección Razón Abierta. Serie Estudios. Pozuelo de Alarcón (Madrid): Editorial UFV, Universidad Francisco de Vitoria.

González Iglesias, Sonia Ma , y Carmen de la Calle Maldonado. 2019. “La mirada del formador como posibilitadora de encuentros significativos”. En Tendencias y retos en la formación inicial de los docentes, 397-406. Universidad Pontificia Comillas. https://dialnet.unirioja.es/servlet/libro?codigo $=733276$.

Guardini, Romano. 2000. El Señor. Meditaciones sobre la persona y la vida de Jesucristo. Buenos Aires: Ed. Lumen.

Juan Pablo II. 1980. “A la Organización de las Naciones Unidas para la Educación, la Ciencia y la Cultura - Unesco”. 2 de junio de 1980. http://www.vatican.va/content/ john-paul-ii/es/speeches/1980/june/documents/hf_jp-ii_spe_19800602_unesco. html. 
López Quintás, Alfonso. 1975. Hacia un estilo integral de pensar. Vol. II. Palma de Mallorca: Universidad de Palma de Mallorca, Facultad de Filosofía y Letras.

López Quintás, Alfonso. 1998. Estética de la creatividad: juego, arte, literatura. Madrid: Rialp.

López Quintás, Alfonso. 2002. Inteligencia creativa: el descubrimiento personal de los valores. Madrid: Biblioteca de Autores Cristianos.

López Quintás, Alfonso. 2009. Descubrir La Grandeza de La Vida: Una Vía de Ascenso a La Madurez Personal. España: Editorial Desclée de Brouwer.

López Quintás, Alfonso. 2014. La ética: o es transfiguración o no es nada. Estudios y ensayos BAC. Filosofía y ciencias 166. Madrid: Biblioteca de Autores Cristianos. López Quintás, Alfonso. 2019. La mirada profunda y el silencio de Dios: una antropología diabólica. Pozuelo de Alarcón (Madrid): Editorial UFV.

Márquez Dorsch, Manuel. 2019. La Transformación Digital centrada en la Persona. Nuevos Modelos de Negocio y Nuevas Formas de Regulación. Independently published.

Mounier, Emmanuel. 1993. Obras Completas. Traducido por Juan Carlos Vila. Vol. 2. Salamanca: Sígueme.

Muñoz García, Juan J. 2015. “Superación del objetivismo mediante experiencias creativas en las filosofía de López Quintás”. Quién. Revista de filosofía personalista, n. ${ }^{\circ} 1: 133-54$.

Orón Semper, José V. 2016. “Virtud como comportamiento ideal o como dinámica interior”. Estudios Filosóficos Polianos, n. ${ }^{\circ}$ 3: 22-28.

Orón Semper, José Víctor. 2018. "Educación centrada en el crecimiento de la relación interpersonal”. Studia Poliana, n. 20 (marzo): 241-62. https://doi. org/10.15581/013.20.241-262.

Pablo VI. 1975. “Evangelii nuntiandi”. La Santa Sede. 8 de diciembre de 1975. http://w2.vatican.va/content/paul-vi/es/apost_exhortations/documents/hf_pvi_exh_19751208_evangelii-nuntiandi.html.

Rupnik, Marko I. 2013. El arte de la vida: lo cotidiano en la belleza. Traducido por Luis Guillermo Robles Prada. Madrid: Fundación Maior.

Weigel, George. 1999. Biografía de Juan Pablo II: Testigo de esperanza. Barcelona: Plaza \& Janés. 